\title{
Test of an Argumentative Skill Deficiency Model of Interspousal Violence
}

Dominic A. Infante

Theresa A. Chandler

Jill E. Rudd

Cleveland State University, J.RUDD@csuohio.edu

Follow this and additional works at: https://engagedscholarship.csuohio.edu/clcom_facpub

Part of the Domestic and Intimate Partner Violence Commons, Family, Life Course, and Society Commons, and the Interpersonal and Small Group Communication Commons

How does access to this work benefit you? Let us know!

\section{Publisher's Statement}

This is an Accepted Manuscript of an article published by Taylor \& Francis in Communication Monographs in June 1989, available online: http://www.tandfonline.com/10.1080/ 03637758909390257

\section{Recommended Citation}

Infante, Dominic A.; Chandler, Theresa A.; and Rudd, Jill E., "Test of an Argumentative Skill Deficiency Model of Interspousal Violence" (1989). Communication Faculty Publications. 55.

https://engagedscholarship.csuohio.edu/clcom_facpub/55

This Article is brought to you for free and open access by the School of Communication at EngagedScholarship@CSU. It has been accepted for inclusion in Communication Faculty Publications by an authorized administrator of EngagedScholarship@CSU. For more information, please contact library.es@csuohio.edu. 


\title{
TEST OF AN ARGUMENTATIVE SKILL DEFICIENCY MODEL OF INTERSPOUSAL VIOLENCE
}

\author{
DOMINIC A. INFANTE, TERESA A. CHANDLER, AND JILL E. RUDD
}

A model of interpersonal physical violence is derived from the aggression literature and then is utilized to investigate interspousal violence. The model posits that verbal aggression is a catalyst to violence when societal, personal, and situational factors are strong enough to produce a hostile predisposition. Unless aroused by verbal aggression, a hostile disposition remains latent in the form of unexpressed anger. The framework suggests that persons in violent. marriages are more verbally aggressive than other people, and also produces the counterintuitive prediction that violent spouses are less argumentative than people in nonviolent marriages. A study is reported which compared clinical cases of abused wives and abusive husbands to a nonclinical population of husbands and wives. Strong support for the hypothesis was observed. Implications of the results are discussed in terms of understanding communication in violent marriages.

A LTHOUGH intrafamily violence occurs in numerous forms, violent behavior A between husband and wife is especially destructive and has received increased attention from researchers (Gelles, 1980; Steinmetz, 1987). Public awareness of the problem has been particularly heightened by the mass media's attention to the battered wife (e.g., the movie, The Burning Bed). The consequences of spouse abuse, besides death, include injury, anxiety, depression, and self-concept damage for both the abused and abusive spouses, and a general decline in the quality of family life. The consequences are not only grave but also more pervasive than commonly believed. A recent national survey (Straus \& Gelles, 1986) suggests that over 1.3 million wives each year in America are victims of serious violence by their husbands. Incidents of minor violence (e.g., pushing, grabbing) were even more numerous, perhaps at least triple the number of serious cases.

The general nature of communication in a situation in which a wife is physically abused is suggested by research on wives' accounts of acute battering episodes (Chandler, 1986a). An episode refers to a communicative routine that has an identifiable opening and closing sequence (Pearce \& Cronen, 1980). A violent episode contains behaviors that result in specific outcomes such as physical or psychological damage (Chandler, 1986a). Violent episodes are punctuated perceptually by participants (see Watzlawick, Beavin, \& Jackson, 1967, for a discussion of punctuation); there may or may not be agreement as to where an episode begins or ends. Also, the beginnings and endings of violent episodes may overlap with periods of nonviolent interaction (see Walker, 1979, for a discussion of the cycle of violence).

The present paper takes a communication approach to this social problem. A model of communication and violence is derived from aggression literature. Relevant research on interspousal violence is reviewed and a test of the validity of applying the model to abused wives and abusive husbands is reported. The approach is communi- 
cation-oriented because it posits that destructive forms of communication such as verbal aggressiveness lead to physical violence, whereas constructive forms such as argumentativeness reduce the chance that social conflict will escalate to physical aggression.

\section{Communication and Violence}

Verbal aggression was defined by Infante and Wigley (1986) as an attack on a person's self-concept. Verbal aggression may substitute for or be used in addition to an attack on the person's position on a particular topic of communication. Infante and Wigley (1986) differentiate verbal aggression from argumentation. Argumentation involves presenting and defending positions on controversial issues and attacking other positions. Thus, the locus of attack distinguishes these two forms of aggressive communication; i.e., a person's self-concept is the locus of attack in the case of verbal aggression whereas the individual's position on an issue is the locus for argument. Generally, a verbally aggressive message attempts to inflict psychological pain, thereby resulting in the receiver's feeling less favorable about self, i.e., suffering self-concept damage.

Although verbal aggression has not been ignored in the vast literature on aggression (for summaries and analyses of aggression research see Bandura, 1973a, 1973b; Berkowitz, 1962; Buss, 1961; Geen \& Donnerstein, 1983a, 1983b; Zillmann, 1979), it has been examined mainly as one of many types of aggression. A recent analysis, however, contends that verbal aggression is worthy of study in its own right, and that it may be valuable to model verbal aggression as a central factor in the cycle of violence (Infante, 1987).

Analysis by Berkowitz (1973) suggested that hostile language serves as a "trigger" for the release of impulsive aggressive responses. In a typical case of impulsive aggression, individuals disagree over some issue, which can be quite trivial; insults are exchanged; and rage mounts as verbal aggression intensifies, culminating in physical violence (Berkowitz, 1983, p. 118). The probability of this pattern is higher when the individuals have a latent disposition toward violence; in that case, aggression-arousing cues, such as hostile language, are particularly instigative (Berkowitz, 1962, pp. 298-299).

Berkowitz' analysis is consistent with the results of several investigators. Toch's (1969) study of men convicted of violent crimes revealed that insults, teasing, and especially attacks on manly status stimulated violence. His study further indicated that these men did not have the verbal skills for dealing with social conflict and thus they viewed violence as their only alternative. It is apparent from Toch's (1969) interviews that there is a language of violence and that physical aggression which does not begin with verbal aggression may be relatively rare. In fact, Zillmann (1979) suggested that verbal aggression is the most frequent antecedent of murder, even more so than revenge. Bandura (1973a) also emphasized the relationship between physical and verbal aggression and contended that people may respond with physical force because they lack alternative social skills such as assertiveness. A study by Rosenbaum and O'Leary (1981), which found that abusive husbands were lower in assertiveness than nonabusive husbands, supports this idea. Also, Gelles' (1974) interviews with families troubled by intrafamily violence reveals the role of verbal aggression: "The majority of incidents of physical violence were caused by the victim's verbal behavior" (p. 156). Some of the types of verbal aggression which 
seemed particularly provoking were attacks on a spouse's sexual ability, the inferior nature of his job, and the spouse's success in providing for the family. Finally, a study by Straus (1974) found that the more married couples were verbally aggressive the more they tended to be physically aggressive.

Felson's $(1978,1982,1984)$ impression management theory of violence helps explain why verbal aggression has such potential for motivating behavior. According to Felson individuals are strongly motivated to maintain a favorable image in social situations and will go to extreme lengths to restore a damaged image. Verbal aggression in the form of an insult, for example, portrays the receiver in a negative light and the person retaliates in order to save face and to prevent a future attack as well. The probability of retaliation is higher when the receiver believes the verbal attack was intentional, illegitimate, and observed by a third party.

Zillmann's $(1979,1983)$ excitation transfer notion complements Felson's ideas in providing an explanation of how verbal aggression can lead to violence. Zillman's model is concerned with the conditions under which an emotional reaction will intensify a subsequent emotional response. According to this framework an act of verbal aggression produces a negative emotional reaction (e.g., anger) and a covert verbal response which facilitates recall of the emotional experience at a later date. The trace left behind can combine additively with subsequent verbally aggressive acts. This intensification of response can energize verbal or physical retaliation. Basically, residues of excitation from previous verbally aggressive acts, if not dissipated, intensify intentions to behave aggressively toward the origin of the verbal aggression. Cognitive mechanisms concerned with appropriateness control whether the intended aggression is inhibited.

Research by Levenson and Gottman $(1983,1985)$ may illustrate the idea that undissipated traces of negative affect can combine additively and constitute a latent hostile disposition. They studied the level of physiological arousal and affect of distressed and nondistressed couples while the spouses talked about high and low conflict topics. The results revealed that when spouses in distressed marriages discussed a high conflict topic the physiological arousal of the pair was related, and distressed couples experienced more negative arousal than nondistressed couples. Of importance to the present model, however, the research also suggested that even before they began talking, distressed couples had higher levels of negative arousal. This may indicate undissipated negative arousal (i.e., anger) from previous interactions.

\section{Derived Model}

Leitner (1984) suggests that a general model of violence in intimate relationships has emerged. This model explains that societal factors (e.g., sexual inequality [Dobash \& Dobash, 1979; Yllo, 1983], culturally sanctioned violence [Gurr \& Bishop, 1976; Steinmetz, 1987], social class [Greenblat, 1983; Straus \& Gelles, 1986]), personal characteristics (e.g., self-esteem [Chandler, Geist, \& Norton, 1983], communication skills [Ponzetti, Cate, \& Koval, 1982], hostile personality [Gillman, 1980], learned helplessness [Walker, 1979]), and situational influences (e.g., stress [Gelles, 1980], alcohol consumption [Coleman, 1980; Gelles, 1980]) predispose the individual to respond to aggressive cues. This predisposition may be viewed as the sum of undissipated residues of negative excitation from previous aggression experiences (Zillmann, 1979, 1983). However, the predisposition usually remains 
latent, in the form of unexpressed anger, until aroused by an aggressive cue, the most common of which may be a verbally aggressive message. In terms of Zillmann's $(1979,1983)$ excitation transfer model, arousal is a key ingredient in the process of violence. Negative response to a verbally aggressive act can combine with negative traces from other aggression instigators, strengthening aggressive behavioral intentions.

Since the societal, personal, and situational factors create a disposition to respond which is energized by verbal aggression, it may be correct to implicate verbal aggression as a catalyst in the complexity of circumstances which surround interpersonal violence. Verbal aggression may be a necessary but not a sufficient condition for the occurrence of interpersonal violence. When societal, personal, and situational factors are not strong enough to produce a latent hostile predisposition, a verbally aggressive message may be ignored or interpreted as "good-natured kidding." The very same message under different conditions (when societal, personal, and situational factors stimulate a hostile predisposition) could provoke a violent act.

A major implication of this model is that a reaction can be blocked if the catalyst is controlled, even though the other ingredients are in place for a reaction. Thus, if verbal aggression is catalytic to violence, training and motivating people to control verbal aggression can impede violence, even though ingredients such as frustrations and alcohol are present. This prospect would seem to rest upon understanding the nature, effects, and causes of verbal aggression.

There appear to be several types of verbally aggressive messages, each probably constituting a form of insult: character attacks, competence attacks, physical appearance attacks, background attacks, maledictions, teasing, ridicule, threats, profanity, and noverbal emblems (Infante \& Wigley, 1986). Since some kinesic behaviors have become functionally equivalent to words (Ekman \& Friesen, 1969), it is not contradictory to maintain that verbal aggression may be expressed nonverbally.

Several reasons for verbal aggression in interpersonal relationships have been suggested (Infante, Trebing, Shepherd, \& Seeds, 1984; Infante, Wall, Leap, \& Danielson, 1984; Infante \& Wigley, 1986): psychopathology (involves transference in which the person attacks with verbally aggressive messages those persons who symbolize or remind the person of a source of unresolved conflict or pain); disdain (expressing extreme dislike for someone); social learning (the individual is conditioned to express anger and to ventilate frustrations; this can include modeling, in which the person learns the consequences of an aggressive behavior vicariously by observing a model such as a character in a television program); argumentative skill deficiency (individuals resort to verbal aggression because they lack the verbal skills for dealing with social conflict constructively).

It would be difficult to rank order the foregoing as causes of verbal aggression in interpersonal relationships. All probably are important to an extent. However, there does appear to be a basis for speculating that an argumentative skill deficiency is a fairly important contributing factor.

The idea that an argumentative skill deficiency is a major cause of verbal aggression is consistent with conclusions by Toch (1969), Bandura (1973a, 1973b), and Gelles (1974) that when individuals do not have verbal skills for dealing with conflict constructively, they resort to verbal aggression, which heightens the probability of further aggression (also see Chandler, 1986a, and Ponzetti, Cate, \& Koval, 
1982). Watkins (1982) contended that lack of effective conflict management skills is a major issue in domestic violence; in violent relationships "communication may be seriously lacking or distorted, due to limited personal skills in communication or to fear of the consequences of honest communication" (p. 54).

It may be that persons who are not skilled at arguing tend to provoke others to use verbal aggression, thus heightening the level of negative arousal in the situation. For instance, when argumentatively inept persons' positions are attacked, because they experience a need to defend, but do not know how to counterattack or rebuild a case, they tend to set up a defense around the object closest to their position on the issue-self (Infante, 1987). An adversary's legitimate position attacks are thus mistaken as personal attacks; i.e., the arguments are taken "personally." The unskilled arguer then feels justified in introducing verbal aggression, thinking he or she is merely reciprocating. This increases the chance that the adversary will resort to verbal aggression because a norm of reciprocity appears to operate when communicating aggressively (Infante, 1988).

In terms of Zillmann's $(1979,1983)$ excitation transfer model, having an argumentative skill deficiency could contribute to the arousal level in a conflict situation because emotional intensification may be more likely when one is unable to attack and defend positions; i.e., verbal aggression may be provoked. Skillful arguing therefore should be a factor in keeping excitation from reaching a destructive level. As specified above, we are not contending that argumentative skill is the only factor involved, only that it explains variability in marital violence.

An argumentative skill deficiency model, therefore, predicts that violence in a marriage is more likely when both spouses are unskilled argumentatively because the probability of verbal aggression is greater. This condition, however, is dangerous physically only when at least one spouse has a latent hostile disposition because of undissipated anger from societal, personal, and situational sources. When one spouse has a latent hostile disposition, verbal aggression can serve as a catalyst for that person's becoming an abuser and the other spouse a victim. If both spouses suffer from latent hostile dispositions, then verbal aggression can be catalytic to both spouses' becoming abusers and victims.

Verbal aggression is a catalyst because of a norm of reciprocity (e.g., Infante, 1988). One act leads to another, with escalating intensity, until physical aggression is likely (Berkowitz, 1962, 1973, 1983). The idea that an initial act of verbal aggression stimulates a verbally aggressive reply appears consistent with Levenson and Gottman's (1983) finding that distressed marital couples, on high conflict topics, reciprocated negative affect. The interrelatedness of a couple's level of negative arousal may be an indication that the individuals have become linked physiologically, and are locked into a pattern of destructive interaction (Levenson \& Gottman, 1983, p. 596). Such a feeling of being locked into a communication pattern may characterize reciprocity in verbal aggression.

The conditions in a marriage should not be as conducive to violence if only one spouse has an argumentative skill deficiency, because the more skillful spouse should be less inclined to reciprocate verbal aggression, hence less likely to create the catalytic reaction of escalating the level of negative arousal. This should be the case even if the less skilled spouse has a latent hostile disposition. Further, the model predicts that violence should be even less likely in marriages in which both spouses are skillful argumentatively and not verbally aggressive, even though one or more 
spouses might have a hostile disposition. Violence should be least likely in marriages in which the spouses are skillful arguers, low in verbal aggressiveness, and do not have latent hostile dispositions.

\section{Relevant Research on Interspousal Violence}

Research on violence between spouses supports ideas in the model concerning communication skill deficiencies and verbal aggression as a catalyst to physical aggression. The studies can be classified on the basis of their focus; some focus on the couples' communication (e.g., Cantoni, 1981) while others focus on the male's communication (e.g., Purdy \& Nickle, 1981) or the family's communication (e.g., Jansen \& Meyers-Abel, 1981). To integrate the literature on verbal aggression with extant research on spousal violence, several of these studies will be reviewed.

Although research on communication in interspousal violence is minimal, many researchers claim that the relationship is an important one (Whitchurch, 1987). The existing literature suggests that because couples who are predisposed toward violence do not possess the skills to communicate effectively (i.e., to solve conflicts, to discuss issues), they resort to physical and verbal aggression. As suggested by the theoretical development in this paper, verbal aggression may trigger physical violence.

Gelles (1974) concludes that "certain verbal assaults made by the victim, if directed at vulnerable aspects of the offender's self-concept, are likely to produce violent reactions" (p. 157). Gelles also emphasizes that verbal deficiencies are a factor in violence: "When the husband and wife are engaged in a verbal fight ... one partner simply runs out of (verbal) ammunition ... and begins to flail away at the other" (p. 163). This is consistent with the argumentative skill deficiency notion.

Several studies from the abuse literature suggest that verbal aggression functions as a catalyst to interspousal violence. Chandler (1986b) found that verbal aggression occurred during episodes of physical abuse. She concluded that "high levels of female verbal aggression may serve to escalate the abuse into more severe physical outcomes" (p. 21). In accounts of psychological abuse, Chandler (1986b) found that five specific types of verbal aggression accounted for a significant portion of the variance in the severity of the violence. These were accusations, rejections, refusals to talk, disconfirmations, and threats. Verbal aggression and psychological abuse were distinguished from each other by Chandler (1986b). Specifically, verbal aggression is seen as a type of potentially abusive behavior whereas psychological abuse refers to a potential consequence of abusive behavior. Psychological abuse can be seen, then, as an outcome of the verbally aggressive behaviors rather than the behaviors themselves.

Walker (1979) identified a consistent pattern to the cycle of violence between spouses that includes the phases of tension-building, battering incident, and makeup. The transition between the tension building phase and the acute battering incident was sometimes triggered by the females' verbal aggression, according to Walker (1979); the women wanted to provoke the acute battering incident to relieve the tension of the first phase and to get the battering over with.

In his examination of verbal aggression and interspousal violence, Straus (1974) found that verbal aggression triggered interspousal violence when it violated the norms of the relationship. Thus, when verbally aggressive acts were defined as a normal part of the couple's discussion, they did not produce an escalation into physical aggression. Conversely, when the verbal aggression was perceived as a 
violation of norms between the partners, it tended to escalate into physical aggression. Straus concluded that physical or verbal aggression tended to produce greater subsequent levels of aggression and violence in these situations.

In addition to studies of couples' communication in abusive relationships, several studies have examined abusive males or females individually. Studies of abusive males suggest that verbal aggression may function as a catalyst to physical violence. In her study, Coleman (1980) found that according to males' perception, 55\% of physically abusive incidents were provoked by the females' verbal aggressiveness. The most prevalent types of verbal aggressiveness that these men reacted to were swearing and attacks on their character. Both of these kinds of verbal aggression are included in the typology presented above.

Based upon their clinical work, Purdy and Nickle (1981) concluded that males in abusive relationships are "victimized by their own lack of communication skills" ( $p$. 111). Other researchers (Balswick \& Peek, 1971; Ganley \& Harris, 1978) have noted that males in violent relationships suffer from an extreme inability to express their emotions verbally. Hence, they channel their emotions into anger which is expressed through physical aggression.

The verbal behavior of females in violent relationships has also been examined. In one study, problem-solving skills of women from abusive and non-abusive relationships were compared (Claerhout, Elder, \& Janes, 1982). The results indicated that non-abused women generated both more alternatives for problem-solving and more effective alternatives than abused women. This supports the idea of a skill defiency for women in abusive relationships. Jansen and Meyers-Abel (1981) also found that women in abusive relationships were skill-deficient in communication, especially in assertiveness.

From these results it is clear that verbal aggression may play a significant role in escalating physical violence between partners. It is also clear that a lack of communication skills may contribute to the predisposition to use both verbal and physical aggression.

\section{Testing the Deficiency Speculation}

Essentially, the model as applied to spouses posits that violence is more likely in a marriage if undissipated anger creates a latent hostile disposition in at least one spouse and the individuals have an argumentative skill deficiency which increases the probability of verbal aggression. Such conditions mean verbal aggression can serve as a catalyst which energizes physical aggression.

Having an argumentative skill deficiency may be indicated when a person is low in trait argumentativeness. Infante and Rancer (1982) defined argumentativeness as a personality trait which predisposes the individual to present and defend positions on controversial issues in communication situations while attempting to refute the positions which others take. When compared to other individuals in argumentative situations, persons who are low in argumentativeness are perceived as less skilled at arguing, less willing to argue, less interested in the discussion, lower in credibility, and less competent communicators (Infante, 1981, 1985; Onyekwere, 1987). A speculation, therefore, according to the deficiency model, would be that spouses in a family troubled by violence are low in trait argumentativeness. This condition may mean the dyad is more prone to verbal aggression, which according to the model is catalytic to violence. This is a counterintuitive prediction because it is commonly 
believed that violent couples argue a good deal. A study by Rosenbaum and O'Leary (1981) which found abusive couples lower in assertiveness provides some basis for the speculation since argumentativeness is assumed to be a subset of assertiveness (Infante, 1987); i.e., one does not have to argue to be assertive, but arguing is inherently assertive. Further support could be inferred from a study by Straus (1974), who found less intrafamily violence in families who discussed conflicts in a rational manner.

An argumentative skill deficiency model of interspousal violence suggests the following hypothesis, which was tested in the present study: Husbands and wives in violent marriages will be less argumentative and more verbally aggressive than husbands and wives in nonviolent marriages.

It probably is apparent that this is a test of a major hypothesis derived from the argumentative skill deficiency model, not a test of the entire theoretical framework. A more comprehensive test would involve locating spouses who have a latent hostile disposition, manipulating verbal aggression with them and also with a control group, and then observing whether verbal aggression is catalytic when it should be according to the model. However, at this point it is not clear how the catalytic idea can be studied in a safe and ethical manner. While it is possible that such a manipulation could be achieved in a tightly controlled therapeutic program, specification of procedures given current knowledge would seem premature. Therefore, at this stage the ex post facto design implied by the hypothesis appeared to be a reasonable first step for obtaining a preliminary assessment of the argumentative skill deficiency model.

\section{METHOD}

\section{Participants}

Four groups of married persons participated in the study. Each represented one of the spouses, either the husband or the wife, in a violent or nonviolent marriage (no couples were in the sample). Although husbands are sometimes the victims of physical abuse (Steinmetz, 1987), the present study focused on clinically defined abused wives and abusive husbands since currently this appears to be the more widespread problem.

The abused wives $(N=60)$ were women who were at one of four shelters for battered wives in a major metropolitan section of a midwestern state. The questionnaire described below was administered to the women individually by a counselor at the shelter.

The abusive husbands $(N=53)$ were males undergoing group therapy for wife-abuse. This group was from a different major metropolitan section of the same state (southwest for the husbands, northeast for the wives). The therapist administered the questionnaire to each husband.

The husbands and wives selected for comparison to the abused and abusive groups also represented available samples (from the northeastern part of the state). Although these two groups are termed "nonviolent," according to the national survey by Straus and Gelles (1986) we could assume around 3\% of the individuals have experienced serious husband to wife violence.

The women assumed to be involved in nonviolent marriages $(N=82)$ were enlisted as research participants in the waiting room of a medical clinic and also in 
the waiting room of a doctor's (gynecologist) office. The males $(N=80)$ were married college students or employees in a factory.

Although available samples have been used in almost all communication research, there was particular concern here because of the possibility that the groups would not only differ in terms of violence, but also in terms of other variables which could explain the results for argumentativeness and verbal aggressiveness. In order to deal with this we measured demographic variables which research suggests are related to interspousal violence: education, family income, whether employed or not, age, years married, number of people living in the home. We then controlled statistically for these variables to determine whether they affected the results.

\section{Measurement}

In addition to the demographic variables, each participant rated himself or herself in terms of argumentativeness and verbal aggressiveness and rated his or her spouse on these two variables.

Argumentativeness was measured by 10 items adapted from the Argumentativeness Scale (Infante \& Rancer, 1982). The items were reworded to reflect arguing with one's husband or wife; e.g., "I get nervous and upset after arguing with him." Rating of the spouse's argumentativeness involved rewording the items so that the research participant's perspective on the spouse was given; e.g., "My husband gets nervous and upset after arguing with me." Coefficient alpha was .74 for ratings of self argumentativeness and .72 for ratings of spouse argumentativeness. While this is in the acceptable range for alpha according to Nunnally (1978), it is lower than what is usual for the scale (e.g., .80s), perhaps a result of converting trait items to a particular context.

Verbal aggressiveness also was measured in this manner. Ten items were adapted from the Verbal Aggressiveness Scale (Infante \& Wigley, 1986) to measure the participant's verbal aggressiveness when talking with his or her spouse; e.g., "I use insults to soften her when she is very stubborn." The items were reworded to reflect perceptions of one's spouse; e.g., "My wife uses insults to soften me when I am very stubborn." Coefficient alpha was .79 for ratings of one's own verbal aggressiveness and .89 for perceptions of own spouse's verbal aggressiveness.

\section{RESULTS}

The four variables (own argumentativeness and verbal aggressiveness and ratings of spouse's argumentativeness and verbal aggressiveness) were analyzed by a multivariate analysis of variance (MANOVA) with sex of the participant as one factor and interspousal violence (two levels, violent and nonviolent) as the second.

The demographic variables (education, family income, whether the participant was employed, age, years married, and the number of people living in their home) were each analyzed by a univariate ANOVA with sex and violence as two independent variables. At least one main effect and/or interaction was significant for each demographic variable. Since available samples were utilized such differences were expected. Some examples of obtained differences are: males were more educated than females, nonviolent were more educated than violent, income was higher for males than females, and income was higher in nonviolent than in violent families.

The demographics were included in this study in anticipation of probable differences and also to be able to control statistically for variance due to demographic 
TABLE 1

Means for argumentativeness and Verbal aggressiveness*

\begin{tabular}{llcccc}
\hline \multicolumn{1}{c}{ Condition } & N & Self ARG & Self VA & Spouse ARG & Spouse VA \\
\hline Male, Violent & 53 & 26.83 & 26.70 & 29.85 & 32.62 \\
Female, Violent & 60 & 25.55 & 26.35 & 33.48 & 35.90 \\
Male, Nonviolent & 80 & 30.41 & 21.30 & 29.20 & 23.84 \\
Female, Nonviolent & 82 & 30.48 & 21.54 & 31.99 & 24.38 \\
\hline
\end{tabular}

* Scale for each ranged from 10 to 50 .

differences. In order to accomplish this, in addition to MANOVA, a multivariate analysis of covariance (MANCOVA) was computed with the six demographic variables as covariates. The results of the MANCOVA were essentially equivalent to those obtained from MANOVA (the probability of the predicted main effect for violence was .001 for both MANOVA and MANCOVA, and respective increases in Wilks' Lambda in going from MANOVA to MANCOVA for violence, sex, and the interaction were $.11, .02, .02$ ). Since the demographic differences had no apparent effects on the hypothesized results, our analysis focused on the MANOVA results. In addition, the MANOVA results are presented because 20 participants were eliminated from the MANCOVA analysis due to missing demographic data. Thus, the MANOVA analysis represents the full sample. Significant main effects were obtained. A two-way univariate ANOVA was then computed for each variable since there was theoretical interest in each (Spector, 1977). The means are presented in Table 1.

The MANOVA main effect for interspousal violence was significant, $F(4,268)=$ $28.90, p<.001$. The univariate $F s$ are reported in Table 2 . Since the size of $F$ indicates the relative contribution of a variable to the multivariate effect (Spector, 1977), it is apparent that the participant's ratings of the spouse's verbal aggressiveness contributed most to the multivariate main effect while the participant's argumentativeness and verbal aggressiveness also contributed substantially. The results strongly support the counterintuitive hypothesis that husbands and wives involved in violent marriages would be lower in self-reported argumentativeness than husbands and wives in nonviolent marriages. The second part of the hypothesis also was supported, that reported verbal aggressiveness would be higher in violent than nonviolent marriages.

The MANOVA effect for $\operatorname{sex}(F(4,268)=3.89, p<.01)$ was due to the participants' ratings of their spouses' argumentativeness. The means were higher when females rated their husbands than when males rated their wives. Such a result,

TABLE 2

UNIVARIATE ANOVA SUMMARY

\begin{tabular}{lcccc}
\hline \hline \multicolumn{5}{c}{ Univariate $F_{\mathrm{S}}$} \\
\hline Effect & Self ARG & Self VA & Spouse ARG & Spouse VA \\
\hline Violence & $28.25^{*}$ & $31.90^{*}$ & 1.64 & $90.65^{*}$ \\
Sex & .38 & .00 & $14.02^{*}$ & 2.48 \\
Interaction & .69 & .11 & .25 & 1.63 \\
\hline \hline
\end{tabular}

$* p<.001$ 
that males are higher than females in argumentativeness, is consistent with earlier research (e.g., Infante, 1982) but is not relevant to the hypothesis.

The MANOVA interaction effect was not significant $(F=.54)$. Thus, the main effect results observed for violence do not need to be qualified as to whether the research participant was a husband or a wife.

A secondary analysis also was conducted to explore relationships relevant to the framework. Table 3 presents the correlations of the variables for each subsample.

Violent and nonviolent marriages were not distinguished by the relationship of argumentativeness and verbal aggressiveness for each spouse. The similarity of the .24 and $.20 \mathrm{rs}$, therefore, does not suggest an individual difference explanation of how argumentativeness and verbal aggressiveness combine in violent marriages.

On the other hand, when the $r$ of -.41 for the argumentativeness of the individuals involved in violent marriages and their perceptions of their spouses' verbal aggressiveness was compared to the $-.17 \mathrm{r}$ observed in nonviolent marriages,

TABLE 3

CORRELATIONS FOR SUBSAMPLES

\begin{tabular}{lccc}
\hline \hline & \multicolumn{3}{c}{ Violent Marriages } \\
\cline { 2 - 4 } & Self VA & Spouse ARG & Spouse VA \\
\hline Self ARG & $.24^{*}$ & $-.22^{*}$ & $-.41^{* * *}$ \\
Self VA & & -.14 & .13 \\
Spouse ARG & & & $.29^{* *}$ \\
\hline \hline
\end{tabular}

\begin{tabular}{lccc}
\hline \hline & \multicolumn{3}{c}{ Nonviolent Marriages } \\
\cline { 2 - 4 } & Self VA & Spouse ARG & Spouse VA \\
\hline Self ARG & $.20^{* *}$ & $.26^{* *}$ & $-.17^{*}$ \\
Self VA & & .01 & $.34^{* * *}$ \\
Spouse ARG & & & .12 \\
\hline \hline
\end{tabular}

${ }^{*} p<.05$

${ }^{* *} p<.01$

${ }^{* * *} p<.001$

the difference was significant $(t=2.00, p<.05)$. This suggests a dyadic interpretation. Violent marriages tended to be characterized by the lower self-reported argumentativeness of one spouse being accompanied by higher perceived verbal aggressiveness of the other spouse. This implies that the low argumentative and high verbally aggressive traits of partners in violent marriages may interact to produce a destructive level of excitation.

\section{DISCUSSION}

This study examined levels of argumentativeness and verbal aggressiveness for husbands and wives in violent and nonviolent marriages. The hypothesis predicted a counterintuitive, yet conceptually grounded, relationship between argumentativeness and interspousal violence-that individuals in violent marriages would be less argumentative than people in nonviolent marriages. Conversely, based upon our idea of the catalytic relationship between verbal aggression and physical violence, it was expected that individuals in violent relationships would exhibit higher levels of 
verbal aggressiveness than individuals in nonviolent relationships. These predictions were supported.

The counterintuitive prediction was based on the relationship established in earlier research between communication skills deficiencies and family violence. Studies indicated that people in violent relationships are less skilled in managing social conflict, lower in assertiveness, and lower in problem-solving skills (Cantoni, 1981; Claerhout, Elder, \& Koval, 1982). Our results suggest husbands and wives in violent marriages are less willing to argue and less able to present and defend positions on controversial issues. This conclusion appears justified since research has established that the Argumentativeness Scale measures motivation to argue and also argumentative competence (Infante, 1981, 1985; Onyekwere, 1987; Rancer \& Infante, 1985). The finding implies that violent couples are not able to talk through issues. A possibility is that the issues which arise in violent and nonviolent marriages are essentially the same, the difference being how communication is used once an issue is recognized in the family situation.

Our model also required that reported verbal aggressiveness would be higher in violent than nonviolent relationships. Support for this prediction is in line with a central notion of the model, that verbal aggression is catalytic to physical violence. Earlier research also supports this possible function (Chandler, 1986b; Coleman, 1980; Straus, 1974). Thus, whereas people involved in nonviolent marriages have a greater tendency to attack their spouses' positions on issues, those in violent relationships are more likely to direct their attacks to their spouses' self-concept. This represents a corruption of the need to attack in social conflict situations, and is a relatively obscured process because, as Whitchurch (1987) has noted, few studies have focused directly on the role of verbal communication in conjugal violence.

Besides the primary analysis, a secondary analysis, from a different perspective, also supported expectations about verbal aggressiveness. For people in violent marriages a moderately strong relationship was observed between the person's reported level of argumentativeness and his or her perceptions of the spouse's verbal aggressiveness. The less persons in violent marriages were argumentative, the more they attributed verbally aggressive behavior to their spouses. In line with this finding, a study by Goldstein and Rosenbaum (1985) found men in abusive relationships were more likely than non-abusive husbands to perceive their wives' behavior as verbally aggressive or self-esteem damaging.

A communication approach to the problem of interspousal violence is illuminating because it reveals that when violence occurs it is not an isolated event in peoples' lives, but is embedded firmly in the process of interpersonal communication which people use to regulate their lives. A communication model provides a basis for implicating one form of communication, verbal aggression, as a catalyst in the circumstances which surround interpersonal violence. It also suggests than another form of communication, argumentation, may serve a constructive function in family conflict situations.

Although these results support our predictions based on the catalytic and argumentative skill deficiency ideas, it should be emphasized that due to the inherent limitations of ex post facto research, the results should be viewed as promising rather than establishing the validity of the present model of interspousal violence. Experimental evidence is needed to determine if modifying argumentative skill has predictable effects on verbally aggressive behavior, which in turn influences the level 
of physical aggression. Moreover, it is necessary to determine individuals' levels of a hostile predisposition according to the specified personal, situational, and societal factors, identify for whom verbal aggression should be catalytic, and then manipulate verbal aggression to see if it is catalytic when it should be and if it is not catalytic when the three factors are generally absent.

An idea that needs to be considered in interpreting the results of this study is that individuals, not marital dyads, were examined. A person's perceptions of the argumentativeness and verbal aggressiveness of self and one's spouse were assessed due to the assumption that how one "thinks the other person is" matters more than how "the person really is." Of course, there are more objective methods of assessing an individual's verbal aggressiveness, and these might yield different results. Whether such noncorrespondence explains variability seems important and we are currently gathering data with married couples to explore the issue.

Actual communication behavior in the marriages represented in our sample was not observed. The behavior in question for violent marriages indeed might be nearly impossible for researchers to view directly. Simply due to the fact that interspousal violent behavior is often unlawful, accounts of the violent episode by the participants may be the major means for studying communication in this context. Truthfulness of accounts is an obvious issue which needs to be addressed in research from this perspective.

The model of interspousal violence developed in this article is a communication model because message behavior in the violent situation and the communication traits of participants are principal explanatory concepts. Besides the argumentative skill deficiency ideas, there are of course other reasons for verbal aggression: psychopathology, disdain, social learning (Infante \& Wigley, 1986). However, an argumentative skill deficiency is the reason which is most clearly a communication concept, and if research produces a treatment model, the communication discipline would be central in terms of delivery since it has specialized since antiquity in teaching the principles of skillful and constructive argument.

\section{REFERENCES}

Balswick, J., \& Peek, C. (1971). The inexpressive male: A tragedy of American society. Family Coordinator, 20, $363-368$.

Bandura, A. (1973a). Aggression: A social learning analysis. Englewood Cliffs, NJ: Prentice-Hall.

Bandura, A. (1973b). Social learning theory of aggression. In J.F. Knuston (Ed.), The control of aggression: Implications from basic research (pp. 201-250). Chicago: Aldine.

Berkowitz, L. (1962). Aggression: A social psychological analysis. New York: McGraw-Hill.

Berkowitz, L. (1973). Words and symbols as stimuli to aggressive responses. In J.F. Knutson (Ed.), The control of aggression: Implications from basic research (pp. 113-143). Chicago: Aldine.

Berkowitz, L. (1983). The experience of anger as a parallel process in the display of impulsive, "angry" aggression. In R.G. Geen \& E.I. Donnerstein (Eds.), Aggression: Theoretical and empirical reviews (Vol. 1, pp. 103-133). New York: Academic Press.

Buss, A.H. (1961). The psychology of aggression. New York: John Wiley.

Cantoni, L. (1981). Clinical issues in domestic violence. Social Casework: The Journal of Contemporary Social Work, $62,3-12$

Chandler, T.A. (1986a). A profile of interaction in acute battering incidents. (Doctoral dissertation, Purdue University, 1986). Dissertation Abstracts International, 47, 1924.

Chandler, T.A. (1986b, October). Perceptions of communication in acute battering incidents. Paper presented at the meeting of the Speech Communication Association of Ohio, Columbus, $\mathrm{OH}$.

Chandler, T.A., Geist, P.R., \& Norton, R.W. (1983, May). The relationship between marital violence, self-esteem, and interaction: An exploratory study. Paper presented at the meeting of the International Communication Association, Dallas, TX. 
Claerhout, S., Elder, J., \& Janes, C. (1982). Problem-solving skills of rural battered women. Americen Journal of Community Psychology, 10, 605-613.

Coleman, K.H. (1980). Conjugal violence: What 33 men report. Journal of Marital and Family Therapy, 6 207-213.

Dobash, R.P., \& Dobash, R.E. (1979). Community response to violence against wives: Charivari, abstract justice and patriarchy. Social Problems, 28, 563-581.

Ekman, P., \& Friesen, W. (1969). The repertoire of nonverbal behavior: Categories, origins, usage, and coding. Semiotica, 1, 49-98.

Felson, R.B. (1978). Aggression as impression management. Social Psychology, 41, 205-213.

Felson, R.B. (1982). Impression management and the escalation of aggression and violence. Social Psychology Quarterly, 45, 245-254.

Felson, R.B. (1984). Patterns of aggressive social interaction. In A. Mummendey (Ed.), Social psychology of aggression: From individual behavior to social interaction (pp. 109-126). Berlin: Springer-Verlag.

Ganley, A.L., \& Harris, L. (1978, August). Domestic violence: Issues in designing and implementing programs for male batterers. Paper presented at the meeting of the American Psychological Association, Toronto.

Geen, R.G., \& Donnerstein, E.I. (Eds.) (1983a). Aggression: Theoretical and empirical reviews, Vol. 1. New York: Academic Press.

Geen, R.G., \& Donnerstein, E.I. (Eds.) (1983b). Aggression: Theoretical and empirical reviews, Vol. 2. New York: Academic Press.

Gelles, R.J. (1974). The violent home. Beverly Hills, CA: Sage.

Gelles, R.J. (1980). Violence in the family: A review of research in the seventies. Journal of Marriage and the Family, 42, 873-885.

Gillman, I.S. (1980). An object-relations approach to the phenomenon and treatment of battered women. Psychiatry, 43, 346-358.

Goldstein, D., \& Rosenbaum, A. (1985). An evaluation of self-esteem of maritally violent men. Family Relations, 34, 425-428.

Greenblat, C.S. (1983). A hit is a hit is a hit ... or is it? Approval and tolerance of the use of physical force by spouses. In D. Finkelhor, R.J. Gelles, G.T. Hotaling, \& M.A. Straus (Eds.), The dark side of families: Current family violence research (pp. 235-260). Beverly Hills, CA: Sage.

Gurr, T.R., \& Bishop, V.F. (1976). Violent nations and others. Journal of Conflict Resolution, 20, 79-110.

Infante, D.A. (1981). Trait argumentativeness as a predictor of communicative behavior in situations requiring argument. Central States Speech Journal, 32, 265-272.

Infante, D.A. (1982). The argumentative student in the speech communication classroom: An investigation and implications. Communication Education, 31, 141-148.

Infante, D.A. (1985). Influencing women to be more argumentative: Source credibility effects. Journal of Applied Communication Research, 13, 33-44.

Infante, D.A. (1987). Aggressiveness. In J.C. McCroskey \& J.A. Daly (Eds.), Personality and interpersonal communication (pp. 157-192). Newbury Park, CA: Sage.

Infante, D.A. (1988). Response to high argumentatives: Message and sex differences. Southern Speech Communication Journal, 54, 159-170.

Infante, D.A., \& Rancer, A.S. (1982). A conceptualization and measure of argumentativeness. Journal of Personality Assessment, 46, 72-80.

Infante, D.A., Trebing, J.D., Shepherd, P.E., \& Seeds, D.E. (1984). The relationship of argumentativeness to verbal aggression. Southern Speech Communication Journal, 50, 67-77.

Infante, D.A., Wall, C.H., Leap, C.J., \& Danielson, D. (1984). Verbal aggression as a function of the receiver's argumentativeness. Communication Research Reports, 1, 33-37.

Infante, D.A., \& Wigley, C.J. (1986). Verbal aggressiveness: An interpersonal model and measure. Communication Monographs, 53, 61-69.

Jansen, M.A., \& Meyers-Abel, J. (1981). Assertive training for battered women. A pilot program. Social Work, 26, 164-165.

Leitner, L.M. (1984). Contextual shifts in interpersonal perceptions of abusing couples. Unpublished paper, Miami University.

Levenson, R.W., \& Gottman, J.M. (1983). Marital interaction: Physiological linkage and affective exchange Journal of Personality and Social Psychology, 45, 587-597.

Levenson, R.W., \& Gottman, J.M. (1985). Physiological and affective predictors of change in relationship satisfaction. Joumal of Personality and Social Psychology, 49, 85-94.

Nunnally, J.C. (1978). Psychometric theory (2nd ed.). New York: McGraw-Hill.

Onyekwere, E.O. (1987). The effects of argumentativeness, ego-involvement, and gender on perceived interpersonal competence. (Doctoral dissertation, Kent State University, 1986). Dissertation Abstracts International, $47,3240$.

Pearce, W.B., \& Cronen, V.E. (1980). Communication, action, and meaning: The creation of social realities. New York: Praeger.

Ponzetti, J.J., Cate, R.M., \& Koval, J.E. (1982). Violence between couples: Profiling the male abuser. The Personnel Guidance Journal, 61, 222-224.

Purdy, F., \& Nickle, N. (1981). Practice principles for working with groups of men who batter. Social Work with Groups, 4, 111-122. 
Rancer, A.S., \& Infante, D.A. (1985). Relations between motivation to argue and the argumentativeness of adversaries. Communication Quarterly, 33, 209-218.

Rosenbaum, A., \& O'Leary, D. (1981). Marital violence: Characteristics of abusive couples. Journal of Consulting and Clinical Psychology, 49, 63-71.

Spector, P.E. (1977). What to do with significant multivariate effects in multivariate analysis of variance. Journal of Applied Psychology, 62, 158-163.

Steinmetz, S.K. (1987). Family violence: Past, present, and future. In M.B. Sussman \& S.K. Steinmetz (Eds.), Handbook of marriage and the family (pp. 725-765). New York: Plenum.

Straus, M.A. (1974). Leveling, civility, and violence in the family. Journal of Marriage and the Family, 36, $13-29$.

Straus, M.A., \& Gelles, R.J. (1986). Societal change and change in family violence from 1975 to 1985 as revealed by two national surveys. Journal of Marriage and the Family, 48, 465-479.

Toch, H. (1969). Violent men. Chicago: Aldine.

Walker, L. (1979). The battered woman. New York: Harper and Row.

Watkins, C.R. (1982). Victims, aggressors, and the family secret. An exploration into family violence. Minneapolis, MN: Department of Public Welfare.

Watzlawick, P., Beavin, J.H., \& Jackson, D.D. (1967). Pragmatics of human communication: A study of interactional patterns, pathologies, and paradoxes. New York: W.W. Norton.

Whitchurch, G.G. (1987, July). Linkages in conjugal violence and communication: A review and critical appraisal. Paper presented at the Third National Family Violence Conference for Researchers, Durham, NH.

Yllo, K. (1983). Sexual equality and violence against wives in American states. Journal of Comparative Family Studies, 14, 67-86.

Zillmann, D. (1979). Hostility and aggression. Hillsdale, N J: Lawrence Erlbaum.

Zillmann, D. (1983). Transfer of excitation in emotional behavior. In J.T. Cacioppo \& R.E. Petty (Eds.), Social psychology: A sourcebook (pp. 215-240). New York: Guilford Press. 
Post-print standardized by MSL Academic Endeavors, the imprint of the Michael Schwartz Library at Cleveland State University, 2018 